\title{
EF4 knockout E. coli cells exhibit lower levels of cellular biosynthesis under acidic stress
}

\section{Dear Editor,}

Recently, a novel elongation factor, termed EF4, was identified in E. coli and shown to catalyze the back translocation of the E- and P-tRNAs (tRNA at E and P sites) to A- and P-sites (Qin et al., 2006). Despite a great number of recent biochemical studies, little remains known as to the precise physiological role of EF4 in vivo. In E. coli, $80 \%$ of EF4 molecules are associated with the cell membrane under optimal conditions, but when cells grow at $\mathrm{pH} 6$ in media containing $100 \mathrm{mmol} / \mathrm{L} \mathrm{MgCl}$, this percentage is reduced to less than 20\% (Pech et al., 2011). Furthermore, it was revealed that overexpression of EF4 in E. coli severely affected cell growth (Qin et al., 2006). However, EF4 knockout $(\triangle E F 4, K O)$ cells exhibited no apparent phenotype in rich LB medium (Shoji et al., 2010). Under certain stresses, such as low temperature or high ionic stress, $\triangle \mathrm{EF} 4$ cells were out-competed by wildtype (WT) cells within a short period of time (Shoji et al., 2010; Pech et al., 2011).

The only organism for which EF4 was shown to be essential is the gastritis pathogen Helicobacter pylori. A systematic knockout analysis in $\mathrm{H}$. pylori revealed that EF4 was essential for cell survival at hostile $\mathrm{pH}$ levels close to the acidic conditions in the stomach (Bijlsma, 2000). We therefore wondered if low $\mathrm{pH}$ values represent a stress condition under which EF4 is required in E. coli. Because the ef4 KO strain in Keio was not designed from the wildtype BW25113 (Karim, 2010), we deleted ef4 in BW25113 strain by ourselves using the $\lambda$ Red system (Datsenko and Wanner, 2000) (Fig. 1A).

In order to establish a relationship between EF4 dependency and $\mathrm{pH}$ conditions, we first prepared LB medium with a $\mathrm{pH}$ of 3,5 , or 7 and observed the growth of WT or $\triangle \mathrm{EF} 4$ (KO) cells at each $\mathrm{pH}$. As shown in Fig. $1 \mathrm{~B}, \mathrm{KO}$ cells grew as well as WT cells at both $\mathrm{pH} 7$ and $\mathrm{pH} 5$, but neither could survive at $\mathrm{pH}$ 3. We then found a difference in cell growth at $\mathrm{pH} 4$ (Fig. 1D). WT cells grew vigorously after a relatively long lag phase, and finally reached saturation at an OD of $2\left(A_{580}\right)$. In contrast, $\mathrm{KO}$ cells remained in lag phase for an extended period of time, to finally reach saturation at about $\mathrm{OD}_{580}=1$. After a 10-fold dilution with $\mathrm{pH} 7$ medium, WT cells regained their normal growth, comparable to that observed for cells grown continuously at $\mathrm{pH} 7$. In contrast, the $\mathrm{KO}$ strain underwent a relatively long lag phase even after increase of $\mathrm{pH}$, and reached saturation at about $\mathrm{OD}_{580}=2$, as observed for WT cells (Fig. 1D). We further found $\triangle E F 4$ cells with a complementary plasmid survived under $\mathrm{pH} 4$ and regain similar growth curves to WT cells under the same conditions (Fig. 1C and 1D). These results clearly demonstrate that EF4 is required for the $E$. coli cell growth at $\mathrm{pH} 4$.

To investigate the overall impact of EF4 deletion on the protein profile of WT or $\triangle \mathrm{EF} 4$ cells, two-dimensional electrophoresis (2-DE) was employed. No protein changes were detected at pH 7 (Fig. S1). Intriguingly, despite the significant slow-down in growth, only six proteins were downregulated in $\mathrm{KO}$ cells at $\mathrm{pH} 4$ (Fig. 1E and 1F). Spots 1-7 were identified as tryptophan synthase subunit $\beta$ (TrpB), D-ribose-binding protein mutant, glutamate-ammonia ligase, L-serine ammonia-lyase (TdcG), rod shape-determining protein (MreB), tRNA-modifying protein (YgfZ), and D-ribose-binding protein mutant D67R, respectively. TrpB catalyzes the last step of the tryptophan biosynthesis (Lane and Kirschner, 1991). D-ribose-binding protein serves as the primary chemoreceptor for chemotaxis (Bjorkman et al., 1994). Glutamateammonia ligase catalyzes the single reaction in the glutamine biosynthesis pathway (Keseler et al., 2013). Three genes ( $s d a A, s d a B, t d c G$ ) code for three l-serine deaminases in $E$. coli, and participate in glycine, serine, and threonine metabolism and cysteine metabolism, and null mutant cells for all three genes grow normally in glucose minimal medium. However, the mutant cells become very large, and many lyse upon subculturing in the same medium lacking tryptophan (Zhang and Newman, 2008). Deletion of $m r e B$ disrupts the typical shape of $E$. coli, enlarging them before finally lysing these cells (Kruse et al., 2005). YgfZ protein modifies tRNAs, and its deletion mutant grows slowly relative to WT, especially at low temperatures (Ote et al., 2006). In summary, these proteins are involved in protein biosynthesis, gluconeogenesis, and cell metabolism processes. Intriguingly, however, none of the six proteins are essential for $E$. coli growth. We speculate that $\mathrm{KO}$ cells do not display signs of physical damage, and can be rescued from growth arrest upon subculturing in medium of $\mathrm{pH} 7$. Hence, when grown to the same $A_{580}$, the cells showed similar protein expression profiles.

Other conditions that lead to a slowing in growth upon ef4 KO were shown to result in decreased translation (Pech 
A

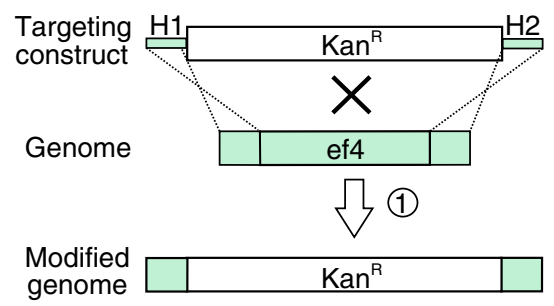

C

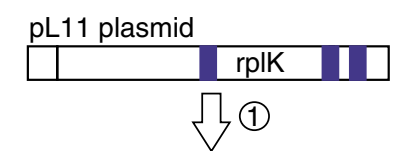

Modified pL11 plasmid

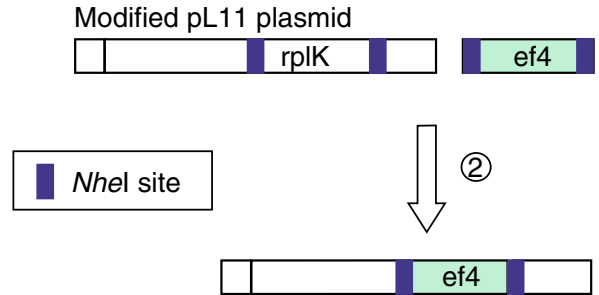

B

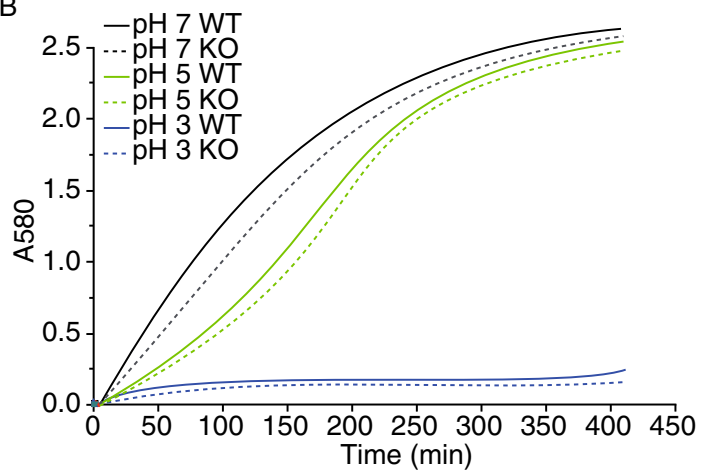

D

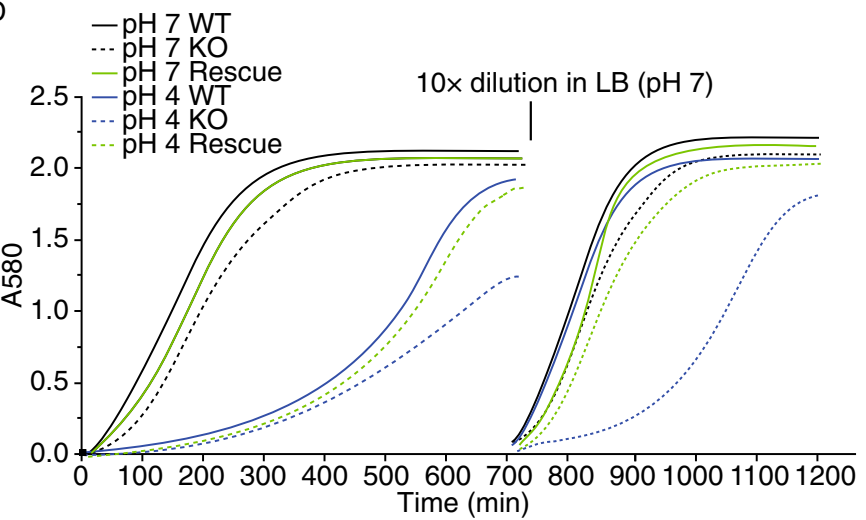

E

$\mathrm{pH} 3$

WT

10

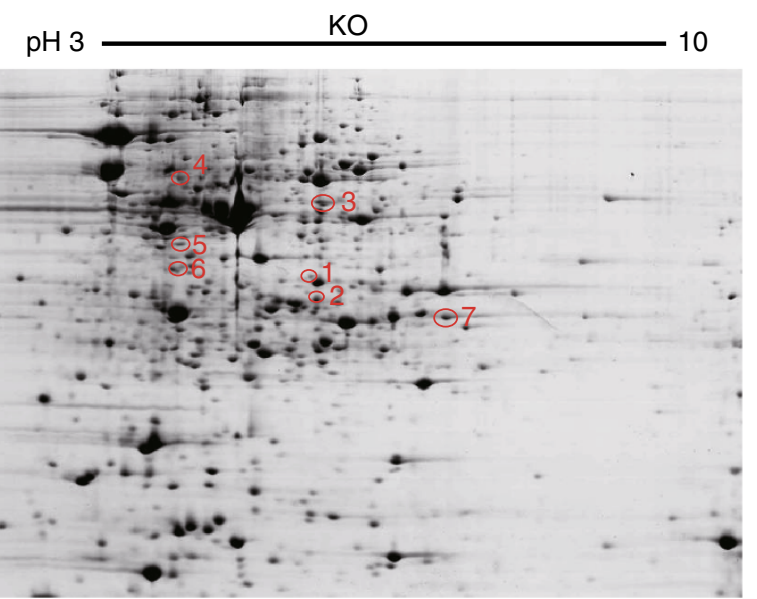

F

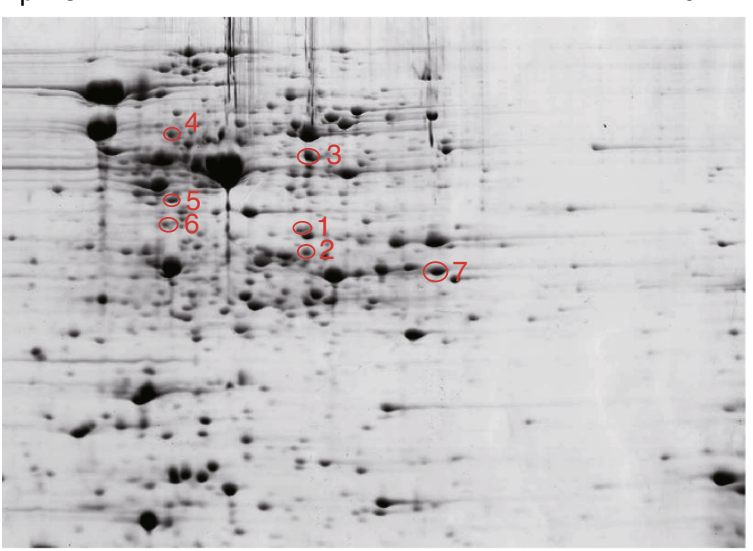

G

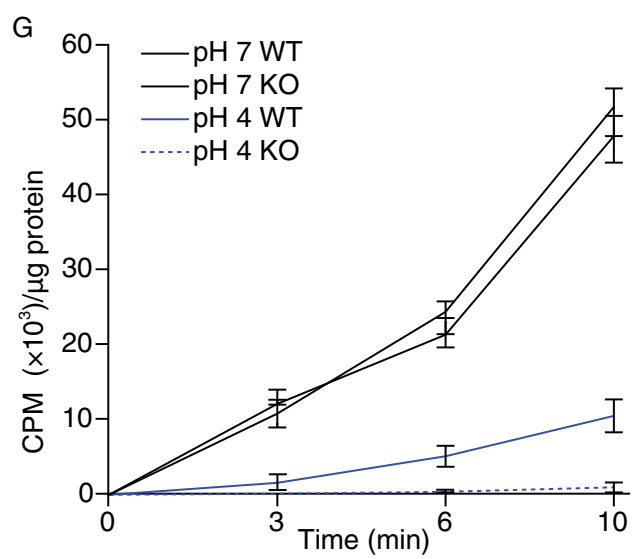


Figure 1. Effects of low pH on the growth and protein translation of ef4-deleted cells. (A) Construction of a singlegene deletion mutant using the $\lambda$ Red system. $\mathrm{H} 1$ and $\mathrm{H} 2$ : homologous to chromosomal sequences of the deleted gene; Step (1) indicates that the $\lambda$-mediated recombination. The targeting construct containing selection marker $\mathrm{Kar}^{\mathrm{R}}$ was transferred to strain BW25113, which contained plasmids expressing the components of $\lambda$ Red system. Then homologous recombination was performed, and the genomic ef4 gene was replaced by $\mathrm{Kar}^{\mathrm{R}}$. Finally, the resistance gene was eliminated using a helper plasmid. (B) E. coli WT cells and $\triangle \mathrm{EF} 4$ cells $(\mathrm{KO})$ were grown in LB medium at $\mathrm{pH} 3,5$ or 7 . (C) Construction of the EF4 rescues plasmid. Step (1) indicates the redundant Nhel restriction site of $\mathrm{pL} 11$ plasmid containing tac promoter was mutated by PCR amplification. Step (2) indicates the ef4 gene amplified from $E$. coli genomic DNA and mutant pL11 digested by Nhel enzyme before ligation to form the EF4 rescue plasmid. (D) E. coli WT cells, $\triangle \mathrm{EF} 4$ cells, and rescued cells were grown in $\mathrm{LB}$ medium at either $\mathrm{pH} 4$ or $\mathrm{pH}$ 7. After cells reached stationary phase, each of the samples was diluted 10 times in LB medium ( $\mathrm{pH} 7$ ). (E) 2-DE images of total proteins in $E$. coli at $\mathrm{pH}$ 4. The number in red circle represents the number of proteins downregulated in $\triangle E F 4$ cells. $(F)$ Quantitative analysis of differentially expressed protein spots from (E). (G) Analysis of translation efficiency in vivo by 35S-methionine incorporation. At times indicated, samples were taken from each culture, and the incorporation of radioactive material was determined.

et al., 2011). Similar phenotypes were observed in yeast, where EF4 was found to be located inside the mitochondria (Bauerschmitt et al., 2008). In yeast, loss of EF4 function caused growth defects under conditions of low temperature and starvation, and importantly, decreased mitochondrial translation (Bauerschmitt et al., 2008). In order to investigate whether translation was decreased in our EF4 KO strain at $\mathrm{pH} 4$ we measured the $\mathrm{S}^{35}$-methionine incorporation rate to assay protein translation in vivo. Our analysis revealed that protein synthesis was inhibited at $\mathrm{pH} 4$ even in WT cells, with levels of protein synthesis at about $20 \%$ relative to that at $\mathrm{pH} 7$ (Fig. 1G). This result was consistent with the slower growth found in WT cells at $\mathrm{pH} 4$. Under normal $\mathrm{pH} 7$ conditions, loss of EF4 made no significant difference (Fig. 1G). Taken together, these findings suggested a translation defect present in the $\triangle \mathrm{EF} 4$ strain at $\mathrm{pH} 4$. As a consequence, fewer amid acids and tRNAs are needed, which in turn induces a decrease in expression of proteins participating in these biosynthesis processes, such as $\operatorname{TrpB}$, glutamate-ammonia ligase, TdcG, and $\mathrm{YgfZ}$. This decrease in translation further impairs the response of $E$. coli cells to the acidic growth conditions, and the expression of proteins required directly or indirectly for adaption to this environment also changed (Fig. 1E and 1F). Collectively, our results suggested that the lack of EF4 affects translation and growth only in unfavorable conditions. Importantly, its high degree of sequence conservation throughout evolution indicates that EF4 may play essential roles for the survival in unfavorable growth conditions other than extreme temperature, high metal concentrations, or low $\mathrm{pH}$, and be in part an evolutionary response to temporary/transient unfavorable conditions.

Because of the association of EF4 with ribosomal movement, and the roles of EF4 in translational processes, we examined the polysome patterns of $\triangle E F 4$ cells throughout the complete growth process, including lag phase $\left(A_{580}=0.1\right)$, log phase $\left(A_{580}=0.4-0.6\right)$, semi-log phase $\left(A_{580}=0.8\right)$, and stationary phase $\left(A_{580}=1.0\right)$. When cells grew at $\mathrm{pH} 7$, the polysome profile of $\triangle E F 4$ cells was similar to that of WT cells (Qin et al., 2006). Cells in the log phase $\left(A_{580}=0.4-0.6\right)$ had an active translation system and protein biosynthesis was efficient. All the classical peaks of ribosomes or ribosomal subunits were present under normal conditions $\mathrm{pH} 7$ (Fig. 2A and $2 \mathrm{C}$ ). When the $\mathrm{pH}$ was lowered to 4, WT cells showed the similar polysome pattern to that at pH 7 (Fig. 2A and 2B). However, the quantity of ribosomes in $\triangle E F 4$ cells was reduced to $40 \%$ of that at $A_{580}=0.1$, and some non-classical ribosomal subunits appeared as indicated with arrows in the top panel of Fig. 2D. Compared to the position of the $30 \mathrm{~S}$ peak in Fig. $2 \mathrm{C}$, the non-classical peak had a smaller sedimentation coefficient, indicating that the biogenesis of the $30 \mathrm{~S}$ subunit was hindered. This situation became more profound when $A_{580}$ reached 0.4 . In addition to premature $30 \mathrm{~S}$ subunits, there were premature $50 S$ peaks, as shown in panel 2 of Fig. 2D. As $A_{580}$ reached 0.6 , there were no further non-classical peaks, but the total quantity of ribosomes did not increase relative to that at $A_{580}=0.1$. In addition, the ratio between polysome and $70 \mathrm{~S}$ ribosomes suggests that the translation efficiency was low. At $A_{580} \geq 0.8, \Delta E F 4$ cells had the same polysome pattern, but exhibited lower levels of polysome and 705 ribosomes than that at $\mathrm{pH} 7$, and the total quantity of ribosomes was much lower than the $4 S$ fraction (Fig. 2D). We also noted that the total quantity of ribosomes in $\triangle E F 4$ cells from different growth phases was always much lower than that of $4 \mathrm{~S}$, which represents the background absorbance of cell lysates at $260 \mathrm{~nm}$ (Fig. 2). Our results suggested that $\triangle E F 4$ cells took $10 \mathrm{~h}$ to overcome subunit maturation defects, reflecting the inhibition of ribosomal biogenesis in $\triangle E F 4$ cells at $\mathrm{pH} 4$. In contrast, the WT strain succeeded in overcoming low $\mathrm{pH}$ induced problems, even though the lag phase was prolonged to $6 \mathrm{~h}$ (Figs. 1 and 2). This data also provides a possible explanation for the null-phenotype observed by Shoji et al. (Shoji et al., 2010), who analyzed pH conditions ranging from 3.5 to 12 . The difference observed here between the two strains only became apparent after $7 \mathrm{~h}$ of culture. In addition, the $70 \mathrm{~S}$ ribosomes and the $30 \mathrm{~S} / 50 \mathrm{~S}$ subunits had reached an equilibrium indicating that the translation machinery will not work efficiently (Nierhaus and Wilson, 2004). In addition, rescued $\triangle E F 4$ cells showed classical polysome patterns (Fig. 2E and 2F).

In summary, our results showed slower growth of $\triangle E F 4$ cells and a lower level of intracellular biosynthesis under 


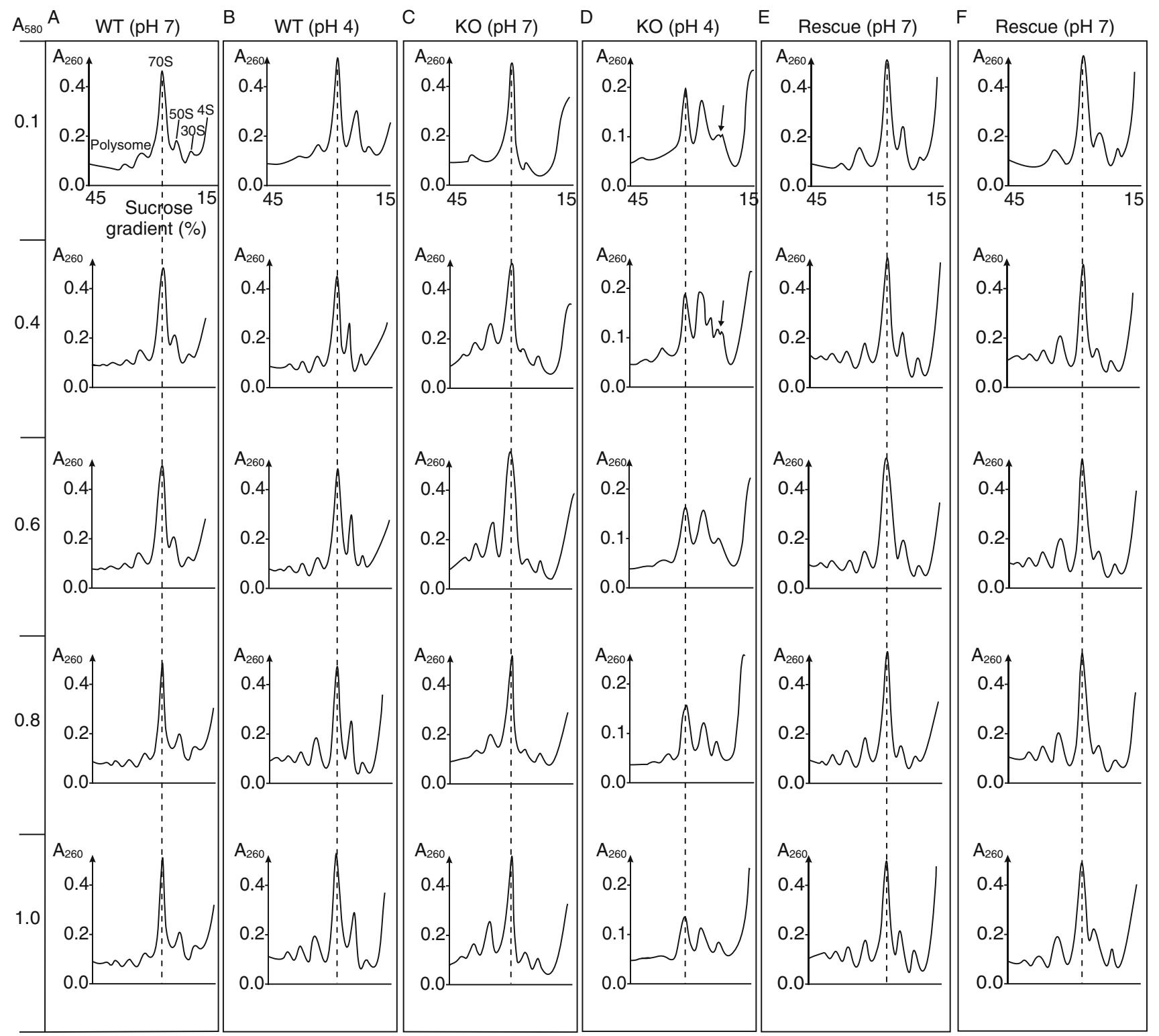

Figure 2. Polysome profile of $\triangle E F 4 E$. coli cells during different growth phases at $\mathrm{pH} 7$ and pH 4. Cell extracts were prepared from $\triangle E F 4$ strains during different growth phases $\left(\mathrm{OD}_{580}=0.1,0.4,0.6,0.8\right.$ or 1.0$)$. The gradient was fractionated while monitoring the absorbance at $260 \mathrm{~nm}\left(\mathrm{~A}_{260}\right)$. The dotted vertical line indicates the monomer peak. (A and B) Polysome profiles of WT cells grown at either $\mathrm{pH} 7$ or $\mathrm{pH} 4$. The ribosome peak-subunits (30S, 50S), monomer (70S) and polysome, and $4 \mathrm{~S}$ peak are indicated. The polysome pattern of cells growing at $\mathrm{pH} 4$ showed no obvious difference to those from cells growing under normal conditions. (C) Polysome profiles of $\triangle E F 4$ E. coli cells grown at $\mathrm{pH} 7$. (D) Polysome profile of $\triangle E F 4$ E. coli cells grown at $\mathrm{pH} 4$. Black arrows indicate non-classical ribosomal subunits. Note that units on the Y-axis for $\mathrm{pH} 4$ samples are half of those for the $\mathrm{pH} 7$ sample. The quantity of ribosomes in $\mathrm{pH} 4$ samples was significantly reduced compared to that in $\mathrm{pH} 7$ with only few polysomes detected. (E) Polysome profile of $\mathrm{KO}$ cells overexpressing EF4 grown at $\mathrm{pH}$ 7. The ribosome peaks showed nearly the same classical patterns as WT at $\mathrm{pH}$ 7. (F) Polysome profile of EF4-rescued $\mathrm{KO}$ cells grown at $\mathrm{pH} 4$. The polysome quantity and patterns under this condition did not change significantly compared to those of cells grown at $\mathrm{pH} 7$. However, the polysome quantity was higher than that in $\Delta \mathrm{EF} 4$ E. coli cells at $\mathrm{pH} 4$, with polysome patterns more classical.

acidic stress. In agreement with growth defects, the EF4depleted strain exhibited a very slower protein translation at $\mathrm{pH} 4$ in vivo. However, there was no difference between WT and $\triangle \mathrm{EF} 4$ cells at normal condition $\mathrm{pH} 7$ (Figs. 1 and 2). This phenotype suggested that EF4 plays an essential and specific role in increasing the fitness of $E$. coli under unfavorable to extreme environmental conditions, where it ensures appropriate/adequate regulation of protein synthesis. Our 
data presented here provide the first time evidence that the translation factor EF4, contribute to protein synthesis and cell growth at unfavorable conditions, explaining why no apparent role was described at optimal growth conditions before.

\section{FOOTNOTES}

This work was supported by grants to Y.Q. from the National Basic Research Program (973 Program) (Nos. 2012CB911001 and 2013CB531200) and the National Natural Science Foundation of China (Grant Nos. 31170756, 31322015, 31270847, and 31000596), CAS grant (KSZD-EW-Z-003), National Laboratory of Biomacromolecules in Institute of Biophysics. We thank Dejiu Zhang for help with the manuscript preparation, and Dr. Joy Fleming for critical reading of the manuscript. We thank Dr. Yong Tao of the Institute of Microbiology, CAS for his kind gifts of plasmids for $E$. coli $\lambda$ Redmediated homologous recombination.

Fang Yang, Zhikai Li, Jia Hao, and Yan Qin declare that they have no conflict of interest. All institutional and national guidelines for the care and use of laboratory animals were followed.

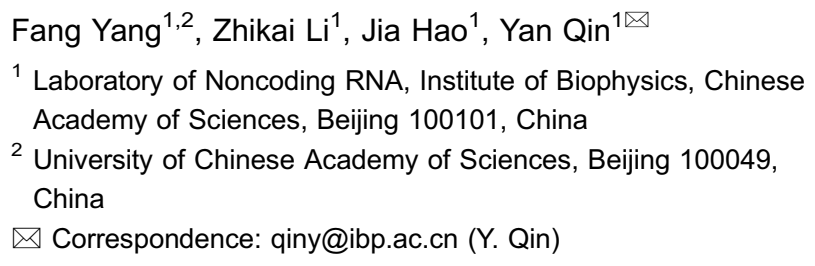

\section{OPEN ACCESS}

This article is distributed under the terms of the Creative Commons Attribution License which permits any use, distribution, and reproduction in any medium, provided the original author(s) and the source are credited.

\section{REFERENCES}

Bauerschmitt H, Funes S, Herrmann JM (2008) The membranebound GTPase Guf1 promotes mitochondrial protein synthesis under suboptimal conditions. J Biol Chem 283:17139-17146

Bijlsma JJE (2000) Identification of loci essential for the growth of helicobacter pylori under acidic conditions. J Infect Dis 182:15661569
Bjorkman AJ, Binnie RA, Zhang $H$, Cole LB, Hermodson MA, Mowbray SL (1994) Probing protein-protein interactions. The ribose-binding protein in bacterial transport and chemotaxis. J Biol Chem 269:30206-30211

Datsenko KA, Wanner BL (2000) One-step inactivation of chromosomal genes in Escherichia coli K-12 using PCR products. Proc Natl Acad Sci USA 97:6640-6645

Karim Z (2010) The importance of the ribosomal elongation factor 4 (LepA). PhD Dissertation, Freie Universität Berlin, Berlin

Keseler IM, Mackie A, Peralta-Gil M, Santos-Zavaleta A, Gama-Castro S, Bonavides-Martinez C, Fulcher C, Huerta AM, Kothari A, Krummenacker $M$ et al (2013) EcoCyc: fusing model organism databases with systems biology. Nucleic Acids Res 41:D605-D612

Kruse T, Bork-Jensen J, Gerdes K (2005) The morphogenetic MreBCD proteins of Escherichia coli form an essential membrane-bound complex. Mol Microbiol 55:78-89

Lane AN, Kirschner K (1991) Mechanism of the physiological reaction catalyzed by tryptophan synthase from Escherichia coli. Biochemistry 30:479-484

Nierhaus KH, Wilson DN (2004) Protein synthesis and ribosome structure: translating the genome (LibreDigital). Wiley, Weinheim

Ote T, Hashimoto M, Ikeuchi Y, Su'etsugu M, Suzuki T, Katayama T, Kato J (2006) Involvement of the Escherichia coli folate-binding protein YgfZ in RNA modification and regulation of chromosomal replication initiation. Mol Microbiol 59:265-275

Pech M, Karim Z, Yamamoto H, Kitakawa M, Qin Y, Nierhaus KH (2011) Elongation factor 4 (EF4/LepA) accelerates protein synthesis at increased $\mathrm{Mg} 2+$ concentrations. Proc Natl Acad Sci USA 108:3199-3203

Qin Y, Polacek N, Vesper O, Staub E, Einfeldt E, Wilson DN, Nierhaus KH (2006) The highly conserved LepA is a ribosomal elongation factor that back-translocates the ribosome. Cell 127:721-733

Shoji S, Janssen BD, Hayes CS, Fredrick K (2010) Translation factor LepA contributes to tellurite resistance in Escherichia coli but plays no apparent role in the fidelity of protein synthesis. Biochimie 92:157-163

Zhang X, Newman E (2008) Deficiency in I-serine deaminase results in abnormal growth and cell division of Escherichia coli K-12. Mol Microbiol 69:870-881
Electronic supplementary material The online version of this article (doi:10.1007/s13238-014-0050-3) contains supplementary material, which is available to authorized users. 